\title{
CAPÍTULO 06: A CONSCIÊNCIA FONOLÓGICA NO NÍVEL SILÁBICO DO INGLÊS: INFLUÊNCIA NA PRODUÇÃO DA PARAGOGE EM MONOSSÍLABOS
}

\author{
CAPÍTULO 06: LA CONCIENCIA FONOLÓGICA EN EL NIVEL DE INGLÉS \\ SILÁBICO: LA INFLUENCIA EN LA PRODUCCIÓN DE PARAGOGE EN \\ MONOSYLABS
}

\section{CHAPTER 06: THE PHONOLOGICAL AWARENESS ON THE SILABIC LEVEL OF ENGLISH: THE INFLUENCE IN THE PRODUCTION OF PARAGOGE IN MONOSYLABS}

\author{
Fábio José de Abreu Moura ${ }^{1}$
}

DOI: https://doi.org/10.31692/978-65-88970-05-8.81-95

\begin{abstract}
RESUMO
A construção deste trabalho realiza-se por uma abordagem quali-quantitativa, desdobrando-se numa pesquisa de campo e de análise de dados. Por meio desta, busca-se comprovar a influência da consciência fonológica no nível silábico do inglês na diminuição da paragoge em palavras monossilábicas, evitando a produção do /i/ final na pronúncia de determinadas palavras. Para tal, baseiase nos estudos de Alves (2012), Aquino (2010), Lamprecht (2012), Blanco-Dutra (2012) e Scherer (2012). Quanto ao processo metodológico da pesquisa-ação, que se fez no âmbito de aprendizagem da língua inglesa numa escola de idiomas, esse se deu inicialmente com um pré-teste em duas turmas, em que uma delas funcionou como turma de controle. A segunda etapa foi a intervenção, com uma sequência didática com foco no input fonológico dos padrões silábicos do inglês. E, por fim, um novo teste para medir a evolução dos participantes. Verificou-se que uma vez adquirida a consciência dos padrões silábicos da língua alvo, o fenômeno da epêntese em final de vocábulo tende a reduzir, evitando a transformação de um monossílabo em dissílabo como resultado desta recorrência aos padrões fonéticofonológicos da língua materna do aprendiz.
\end{abstract}

Palavras-Chave: Consciência fonológica, Padrões Silábicos, Língua Inglesa.

\section{RESUMEN}

La construcción de este trabajo se realiza mediante un enfoque cualitativo y cuantitativo, desplegándose en una investigación de campo y análisis de datos. A través de esto, buscamos probar la influencia de la conciencia fonológica en el nivel silábico del inglés en la reducción de la paragoge en palabras monosilábicas, evitando la producción de / i final en la pronunciación de ciertas palabras del portugués brasileño. Para ello, se basa en los estudios de Alves (2012), Aquino (2010), Lamprecht (2012), BlancoDutra (2012) y Scherer (2012). En cuanto al proceso metodológico de investigación acción, que se llevó a cabo en el contexto del aprendizaje de la lengua inglesa en una escuela de idiomas, este se realizó inicialmente con un pre-test en dos clases, en las que uno trabajó como grupo de control. La segunda etapa fue la intervención, con una secuencia didáctica centrada en el input fonológico de los patrones silábicos del inglés. Y, finalmente, una nueva prueba para medir la evolución de los participantes. Se constató que, una vez adquirido el conocimiento de los patrones silábicos de la lengua extranjera, el fenómeno de la epéntesis al final de una palabra tiende a reducirse, evitando la transformación de un monosílabo en un disílabo como consecuencia de esta recurrencia a los patrones fonético-fonológicos de la lengua materna del alumno.

Palabras Clave: Conciencia Fonológica, Patrones Silábicos, Lengua Inglesa

\section{ABSTRACT}

The development of this work is carried out by a qualitative-quantitative approach, unfolding in some field research and data analysis. The aim of this study is to verify the influence of phonological awareness on the syllabic level of English in the reduction of paragoge in monosyllabic words, avoiding

\footnotetext{
${ }^{1}$ Mestrado em Letras - Linguística, UFPE, fabio.jose@ufpe.br
} 
the production of the final /i/ in the pronunciation of certain words. For this, it is based on the studies of Alves (2012), Aquino (2010), Lamprecht (2012), Blanco-Dutra (2012) and Scherer (2012). As for the methodological process of action research, which was done in the context of English language learning in a language school, this was initially done with a pre-test in two classes, one of which functioned as a control group. The second stage was the intervention, with a lesson plan focusing on the phonological input of the syllabic patterns of English. And, finally, a new test to measure the evolution of the participants. It was verified that once the awareness of the syllabic patterns of the target language had been acquired, the epenthesis phenomenon at the end of the word tended to be reduced, avoiding the transformation of a monosyllable into a syllable as a result of this recurrence to the phonologicalphonological patterns of the mother tongue of the apprentice.

Keywords: Phonological Awareness, Syllabic Patterns, English Language.

\section{INTRODUÇÃO}

A estrutura de sílaba da língua inglesa pode causar ao falante da língua portuguesa certas dificuldades linguísticas, isto é, dificuldades de pronúncia, já que a sílaba do inglês se compõe e se relaciona com a fala de modo distinto à do português. $\mathrm{O}$ aprendiz de uma língua estrangeira nos níveis iniciais tenderá a adaptar a estrutura que já conhece de sua língua materna à nova estrutura linguística em contato.

As ocorrências de transferências fonológicas entre línguas podem estar relacionadas a questões grafo-fônico-fonológicas. No caso do português, tal relação entre as letras e os sons por elas representados são consideradas rasas ou transparentes, ou seja, são previsíveis pelo falante. No entanto, mesmo que o português e o inglês façam uso do mesmo sistema alfabético, o vínculo entre escrita e produção sonora é diferente em cada um desses sistemas (ALVES e BARRETO, 2012a).

Aquino (2010) diz que o português é uma língua que se caracteriza pela terminação vocálica em sua estrutura silábica. Por esse motivo, quando emprestamos palavras de outras línguas com terminações não permitidas em coda silábica no português, como ' $c l u b$ ', tendemos a acrescentar uma vogal final; por isso o português é conhecido por ser uma língua de epênteses - entendendo epêntese como a intercalação de fonema não etimológico no interior de um vocábulo, por acomodação articulatória, eufonia, ou analogia ${ }^{1}$.

Quando consoantes oclusivas (/p/, /b/, /m/, /t/, /d/, /n/, /k/, /g/) ocorrem em final de palavra, por exemplo, o falante brasileiro do inglês tende a inserir a vogal "i” após a consoante. Isso ocorre porque, no inglês, essas consoantes podem ser pronunciadas com travamento, ou sem a soltura da corrente de ar, e, no português, essa estrutura dificilmente acontece. Segundo Aquino (2010), é somente por meio do reconhecimento da estrutura silábica que o falante tem

${ }^{1}$ Cf. Grande Dicionário Houaiss da Língua Portuguesa. 
condições de julgar o que são estruturas bem ou malformadas, isto é, poderá apontar quais são as combinações de segmentos possíveis na língua-alvo: "crê-se que a capacidade de evidenciar o número de sílabas das palavras da L2 pode vir a impedir a produção de epênteses vocálicas de caráter indevido" (ALVES, 2012b, p. 175-176).

Quando o falante é capaz de reconhecer e manipular os sons de uma língua, diz-se que este possui consciência fonológica. O estudo de consciência fonológica é realizado por diversos estudiosos, a título de exemplo tem-se Lamprecht (2012), Blanco-Dutra (2012), Aquino (2010), Scherer (2012), e Alves (2012).

Com isso, a temática desta pesquisa se volta ao estudo da formação de um metaplasmo (desvio da correta composição fonética da palavra) por paragoge, ou o acréscimo de um fonema não etimológico no final de uma palavra ${ }^{2}$, em monossílabos do inglês, por falta de consciência fonológica em relação ao nível silábico. Assim, a problemática é: a (não) consciência dos padrões silábicos do inglês influencia na pronúncia de palavras monossilábicas?

Este tipo de pesquisa é relevante para exemplificar problemas resultantes do pouco ou nenhum trabalho do tipo nas aulas de inglês, buscando contribuir com uma nova visão acerca do tema e, assim, ressaltar sua necessidade.

A pesquisa se baseia em monossílabos para representar a transformação destas em dissílabos pelo acréscimo de uma vogal epentética em final de vocábulo. Pode-se ocorrer em palavras de qualquer outro tamanho, mas escolheram-se propositalmente as monossilábicas para demonstrar a transformação causada pela paragoge de modo simplificado.

A metodologia é de cunho bibliográfico, pautada no estudo de materiais teóricos, porém, com foco maior na pesquisa de campo, apresentando a realidade das aulas de língua inglesa. $\mathrm{E}$ a análise dos dados é feita de forma qualitativa e quantitativa, por meio de transcrições fonéticas para representar as pronúncias dos participantes, e medir em porcentagem o grau de acertos, de erros e, por fim, de evolução.

Primeiramente, foi realizado um pré-teste, em duas turmas, para medir o nível de consciência fonológica dos alunos. A partir destes primeiros dados, observou-se a formação da vogal epentética. Uma turma serviu de controle, e a outra recebeu a intervenção. Após isso, um novo teste foi feito para medir a (não) evolução de ambas as turmas.

É utilizada, neste artigo, a transcrição de segmentos entre colchetes e a transcrição de fonemas entre barras quando há necessidade. Quando a intenção é representar a letra propriamente dita, usam-se aspas.

\footnotetext{
${ }^{2}$ Cf. Ibidem.
} 


\section{FUNDAMENTAÇÃO TEÓRICA}

\section{CONSCIÊNCIA FONOLÓGICA}

A consciência fonológica envolve um grau de entendimento que vai além dos sons da língua. Remete a uma capacidade de reflexão e manipulação de componentes menores de uma palavra, caracterizando uma habilidade de análise e julgamento consciente do estímulo auditivo, e, desta forma, "o indivíduo pode expor e inferir como os sons se combinam, quais são essas combinações, se são possíveis ou não, quais ocorrem e quais não ocorrem em sua língua” (ALVES, 2012a, p. 31).

Para isso, segundo Scherer (2012, p. 23), o falante deve atentar à estrutura da palavra como um todo e também à sua segmentação em sons individuais, ignorando o significado do vocábulo, e, assim, terá entendido que a palavra possui segmentos que podem ser alterados, reformulados e recriados: "dessa forma, o falante pode se concentrar na maneira como os morfemas se organizam dentro de uma palavra, ou no modo como as palavras se organizam em sintagmas, ou, ainda, como as palavras são constituídas pela cadeia de sons, e daí por diante" (ALVES, Ibid., p. 29).

Dois termos chaves caracterizam a noção de consciência fonológica, segundo Alves, são eles: reflexão e manipulação.

\footnotetext{
"Reflexão, no caso da aquisição de uma L2, implica notar o inventário de sons da língua-alvo, e, por conseguinte, as diferenças entre os sistemas de sons da L1 e da L2. Requer que o aprendiz se mostre conhecedor, implícita ou explicitamente, dos ambientes fonológicos em que tais sons podem figurar, bem como do modo como esses sons podem combinar-se entre si para formar unidades maiores, tais como sílabas e palavras. Já o termo manipulação das unidades sonoras da L2 significa operar sobre os sons da língua a ser adquirida, através de atividades como de segmentação, exclusão e transposição de sons" (Ibid., p. 172 - grifos do autor).
}

Assim, quando o aprendiz passa a refletir o funcionamento e propriedades de uma língua, mais ciente ele se torna das características particulares desta, e ainda, o processo de manipulação tornar-se-á lógico, já que, manipular exige conhecimentos específicos resultantes da reflexão.

Blanco-Dutra, Scherer e Brisolara (2012, p. 82) afirmam que "quando as crianças ingressam na escola, já trazem com elas habilidades fonológicas importantes para a aquisição da língua escrita", porém, Aquino (2010) diz que é importante entender que possuir consciência fonológica na L1 não garante que o aprendiz possuirá também na L2. Para ela, o processo que o aluno faz para adquirir certo grau de consciência fonológica na língua estrangeira se dá de forma distinta na língua materna por causa dos padrões silábicos que são desiguais. 
A noção de consciência fonológica pode ser dividida em diferentes níveis, com maior ou menor grau de complexidade a depender do nível em questão. Não há um número exato de níveis, mas a maioria dos autores, como Lamprecht (2012), Alves (2012), Aquino (2010), Scherer (2012), entre outros, costumam dividi-los em: consciência no nível dos fonemas, consciência no nível das unidades intrassilábicas e consciência no nível das sílabas.

Esta pesquisa busca que os alunos adquiram primordialmente a consciência fonológica no nível da sílaba, pois pode evitar a problemática da pronúncia inadequada decorrente da pouca ou nenhuma capacidade de reflexão e manipulação das sílabas em inglês.

\section{NÍVEIS DE CONSCIÊNCIA FONOLÓGICA}

\section{NÍVEL DOS FONEMAS}

No nível dos fonemas, o indivíduo precisa reconhecer e manipular as menores unidades sonoras de valor distintivo na língua, ou seja, segmentar palavras em sons, juntar sons para formar palavras, identificar palavras que iniciam ou terminem com o mesmo som de outra palavra e excluir determinados sons para formar palavras diferentes. Segundo Aquino (2010, p.22-23), talvez este seja o nível mais complexo.

Nos estudos de língua estrangeira, o nível fonêmico diz respeito aos sons distintivos entre a L1 a e L2, sons estes que podem ocorrem em uma língua e na outra não, o que muitas vezes resulta em confusão para o aprendiz. Em situações de fala em que o aprendiz necessita usar um som que não possui propriedade, ele possivelmente irá recorrer ao inventário fonéticofonológico de sua língua materna, e tenderá, segundo Alves (2012b, p.180), a processar a palavra thanks com o som de /f/ ao invés de / $\theta /$, por exemplo.

\section{NÍVEL DAS UNIDADES INTRASSILÁBICAS}

No nível intrassilábico, o indivíduo possui consciência das unidades intrassilábicas de ataque e rima. Ele é, portanto, capaz de manipular rimas e aliterações característicos dessas unidades (AQUINO, 2010, p. 22).

Há unidades menores que uma sílaba e há outras maiores que um fonema que também podem ser manipuladas. O ataque ou onset, de uma sílaba, são os segmentos que antecedem a vogal da sílaba. Por sua vez, tudo que não é onset numa sílaba é chamado de rima ${ }^{3}$, que pode abranger a vogal da sílaba (núcleo silábico) e ainda a coda (os segmentos consonantais que vêm

\footnotetext{
${ }^{3}$ Quando se fala em rima silábica, fala-se dos segmentos de uma única sílaba. Já a rima da palavra pode incluir mais do que uma sílaba, isto é, podem apresentar sons iguais desde a vogal ou o đitongo tônico até o último fonema (ALVES, 2012).
} 
após o núcleo silábico). Logo, o aprendiz, neste nível, desenvolverá consciência tanto quanto à rima (Fact e tract) quanto às aliterações (grave e grade) (ALVES, 2012a, p. 35).

"No que diz respeito a esse nível de consciência, uma grande fonte de dificuldade para o aprendiz diz respeito a casos de sequências consonantais finais do inglês cuja relação grafemafonema não se mostra transparente" (ALVES, 2012b, p. 178). O autor exemplifica as palavras missed [mist] e list [1ıst] como uma dificuldade para aprendizes iniciantes, falantes do português brasileiro, em reconhecer que estes vocábulos rimam, por julgarem que as grafias não são semelhantes. Em casos como este, é preciso atentar não à forma escrita das palavras, mas à oral.

\section{NÍVEL DAS SÍLABAS}

E finalmente, o nível silábico, foco maior deste trabalho.

Para Alves (2012a, p. 34), a consciência fonológica no nível silábico é claramente observada na capacidade de segmentar as palavras em sílabas, adquirida antes mesmo da alfabetização da criança: "no nível silábico, o indivíduo é capaz de segmentar as palavras, contando o número de sílabas, invertendo a ordem delas, adicionando ou excluindo sílabas e produzindo palavras que comecem ou terminem com a mesma sílaba de outra palavra" (AQUINO, 2010, p. 22).

No inglês, por exemplo, o aprendiz deverá ser capaz de dizer que a palavra thanks

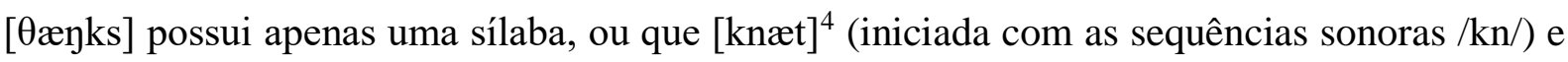
[kæłh] (encerrado pelos sons /łh/) - que não são palavras reais ${ }^{5}$-, são impossíveis de pertencer ao inventário de palavras da língua inglesa (já que, em palavras como knife o som /k/ não é pronunciado, e para th será representado por um único fonema $/ \theta /$ ou /ð/); assim como deve julgar não palavras como [kṛæt] (iniciada com a sequência sonora $/ \mathrm{kṛ} /$ ), ou sart [saṛt] (finalizada com a sequência de sons /rit/) como formas possíveis de ocorrer na língua (ALVES. 2012b, p. 175).

O aprendiz deve também ser capaz de refletir acerca de palavras terminadas com a letra “e”, que na maioria das vezes não será pronunciado (SILVEIRA, 2004). Além disso, há também as consoantes plosivas /p, t, k, b, d g/ que podem aparecer em posição final no inglês e no português não (ALVES, 2012b, p. 175).

“[...] deve ser considerada a capacidade de os aprendizes reconhecerem as vogais que

\footnotetext{
${ }^{4}$ Palavra criada por Alves (2012b, p.175) à título de exemplo de sequência de sons que não podem ocorrer em inglês.

5 "Não Palavras - Palavras inventadas sem significado apresentando padrões segmentais e silábicos possíveis de ocorrerem em uma dada língua. São chamados também de logatomos ou pseuđopalavras" (LAMPRECHT et al, 2012, p. 263 (Glossário) - grifo do autor).
} 
caracterizam os picos de sonoridade, que constituem os elementos de maior proeminência nas sílabas" (Idem): o entendimento fonológico da sílaba em inglês, pode melhorar a pronúncia das palavras levando em consideração a sílaba tônica, já que esta, quando identificada dará ritmo à palavra. Mas, segundo Aquino:

\begin{abstract}
“[...] para que o aprendiz possa aplicar regras de acentuação da LE corretamente, ele necessita de um conhecimento mínimo a respeito dos padrões silábicos ou estrutura da sílaba na língua-alvo, além da necessidade de processar as diferenças entre as duas línguas. Quando o aprendiz não possui consciência a respeito dessas diferenças entre sua língua materna e a língua-alvo, ele tende a transferir padrões conhecidos de sua primeira língua, muitas vezes de forma inadequada" (2010, p. 15).
\end{abstract}

Um dos casos mais recorrentes dessas adequações dos padrões silábicos da L2 são chamados de paragoge.

\title{
PARAGOGE
}

Fundamentado em BAGNO (2007, p. 09) a definição de paragoge - também chamada de epítese - é o acréscimo de um segmento sonoro no final da palavra, por exemplo, ante > antes. Na língua portuguesa, estas ocorrências normalmente são resultadas de metaplasmos ${ }^{6}$ por acréscimo final resultante da mudança diacrônica da língua.

O fenômeno da paragoge é muitas vezes confundido com o da epêntese. Bagno (2007, p. 08) considera a epêntese como "o acréscimo de um segmento sonoro no meio da palavra: stella > estrela; humile > humilde; úmero > ombro". O que pode causar esta confusão é o uso recorrente do termo "epêntese", nas literaturas, em situações de acréscimo do fonema em finais de palavras, quando na verdade esse fenômeno recebe o nome de paragoge. Isso também pode estar relacionado ao fato de associar o acréscimo da vogal /i/ em qualquer posição como epêntese, sem levar consideração a posição em que isto corre. Há ainda, segundo Silva (2012, p. 2), autores que classificam a paragoge como uma subclasse da epêntese.

"No aportuguesamento de vocábulos estrangeiros, é comum a paragoge, para evitar que a palavra termine em consoante: club > clube; surf > surfe; chic > chique $($ BAGNO, 2007, 09)". Essas adaptações resultam da tentativa de transformar o padrão silábico do inglês no padrão CV do português. Silva (2015, p. 95.) diz que quando "pbkg" ocorrem em final de palavra o falante brasileiro de inglês tende a inserir uma vogal /i/ na pronúncia após a consoante, sendo este efeito da mesma tentativa de moldar a coda final da silaba do inglês para torná-la semelhante à formatação silábica do português.

\footnotetext{
${ }^{6}$ Um metaplasmo é uma mudança na estrutura de uma palavra, ocasionada por acréscimo, remoção ou deslocamento dos sons de que ela é composta. Na mudança do latim em português é possível detectar alguns metaplasmos que agiram com regularidade nessa transformação (BAGNO, 2007, p. 08).
} 
Outra situação comum é em palavras terminadas em "e" ortográfico. Silveira (2004) estuda em sua pesquisa tais ocorrências, mostrando que os aprendizes tendem a encontrar dificuldade na oralização destes vocábulos. Então, entende-se que os casos mais recorrentes de paragoge na língua inglesa, produzidos por falantes do português brasileiro, é resultado de uma estratégia para transformar uma estrutura da L2 numa existente em sua língua materna. Silva (2012) exemplifica esta adaptação com o fato do Português Brasileiro (PB) ser apoiado na vogal e, por isso, em ocorrências de letras mudas, o falante tende a inserir a epêntese ou a paragoge para tentar "corrigir" tal estrutura.

\footnotetext{
"Dada essa dificuldade, há a tendência, por parte do falante brasileiro aprendiz de inglês, a fazer uso da epêntese como estratégia de reparo silábico, de modo a enquadrar a consoante que ocuparia a posição de coda do inglês dentro do padrão CV. Ex: big [brgi], map [mæpi], rat [rætfi]" (ALVES, 2004, p. 71-72).
}

Em suma, os aprendizes do inglês precisam compreender a estrutura silábica da língua em questão, intrinsicamente falando, dado a problemática deste trabalho, a compreensão de que a estruturação da coda na sílaba se dá de modo diferente entre o português e o inglês.

\section{METODOLOGIA}

Com o objetivo de testar a hipótese da pesquisa, foi realizada uma pesquisa-ação de cunho intervencionista. Há pequenas variações quanto a definição de uma pesquisa-ação. Por exemplo, Lima Jr. (2010) classifica as seguintes etapas:

1. Identificação de um problema/situação que exige mudança;

2. Coleta de dados;

3. Formação de uma hipótese;

4. Intervenção;

5. Avaliação dos efeitos da intervenção;

6. Disseminação.

Após a identificação de uma situação-problema na produção de palavras monossilábicas em inglês (anteriormente mencionado), duas turmas foram escolhidas para a pesquisa. Em ambas, todos os participantes eram brasileiros e possuíam idade entre 15 e 16 anos. Estes cursavam o nível básico 2 do curso de inglês em uma escola de idiomas na cidade de João Alfredo, estado de Pernambuco (PE). As aulas aconteciam três vezes por semana: às segundas, 
terças e quintas-feiras, e tinham uma carga horária de 6 horas semanais. A turma A era do turno da manhã e foram entrevistados 13 participantes; a turma $\mathrm{B}$, que funcionava à tarde, contou com 8 participantes.

No primeiro encontro, todos esses alunos foram submetidos a um pré-teste de pronúncia elaborado pelo pesquisador. Cada participante teve a oportunidade de ler as 10 (dez) palavras antes de iniciar - Lima Jr. (2010) diz que isso torna a gravação da pronúncia mais apurada. Foram propositalmente selecionadas apenas palavras monossilábicas para aferir se os participantes a transformariam em dissílabas por meio da inserção de um /i/ paragógico. É importante ressaltar que não foi delimitado um tempo máximo para a oralização das palavras.

Quanto aos instrumentos para o levantamento de dados utilizou-se um Smartphone da marca Motorola, cujo modelo era Moto G5s Plus. Quanto ao aplicativo de captação de áudio, utilizou-se o "Audio Recorder" versão 2.01.41.

Quadro 01: Palavras utilizadas no pré-teste

\begin{tabular}{|c|c|}
\hline Palavras & Transcrição fonética \\
\hline Cup & {$[\mathrm{k} \wedge \mathrm{p}]$} \\
\hline Robe & {$[\mathrm{rovb}]$} \\
\hline Job & {$[\mathrm{dgab}]$} \\
\hline Club & {$[\mathrm{kl}$ b] $]$} \\
\hline Stamp & {$[\mathrm{stæmp}]$} \\
\hline Black & {$[\mathrm{blæk}]$} \\
\hline Flag & {$[\mathrm{flæg}]$} \\
\hline Horse & {$[\mathrm{hors}]$} \\
\hline Have & {$[\mathrm{hæv}]$} \\
\hline Word & {$[\mathrm{wrdd}]$} \\
\hline
\end{tabular}

Fonte: própria (2019)

Após as gravações, a partir do segundo encontro deu-se início à intervenção. A decisão de qual turma receberia intervenção foi feita pela quantidade de aprendizes, que na turma A era bem maior que na turma $\mathrm{B}, \operatorname{logo}$, mais pessoas aperfeiçoariam sua pronúncia. Então, a turma $\mathrm{A}$ recebeu aulas de consciência fonológica no nível silábico e a turma B funcionou como turma de controle. Durante o período de intervenção, além das aulas normais, o grupo de pesquisa teve 12 horas concretizadas. A cada encontro, 01 hora se destinou à intervenção, sendo 03 horas por semana, e totalizando 06 horas ao objetivo. Enquanto que no grupo de controle, os alunos tiveram apenas aulas normais.

As aulas de pronúncia foram conduzidas pelo pesquisador, tomando como base o que dizem Barreto e Alves (2012, p.232) em relação à pronúncia. Para eles, o ensino de pronúncia

\footnotetext{
${ }^{7}$ Oferecido pela Sony Mobile Communication e disponível gratuitamente para download na Play Store.
} 
precisa levar em consideração as necessidades do aluno, assim como seu contexto, localidade, instituição e ainda as variedades linguísticas de sua L1, e, apenas após estabelecer esses fatores, o professor pode estruturar o conteúdo.

Ainda de acordo com os autores, a abordagem deve ser comunicativa e contextualizada, pois uma abordagem dos sons de forma isolada não alcança resultados eficientes em curto prazo, além de se tratar de uma abordagem mecanicista. Pensando nesses pretextos e no objetivo da pesquisa, optou-se por fazer uso do manual de pronúncia de Rosane Silveira (2004, p. 221), disponível em sua tese de doutorado.

Foram selecionadas dentre as diversas atividades, algumas mais relevantes e que mais se enquadram nos critérios da pesquisa. Atrelou-se a ordem dos assuntos do manual às explicações e discussões em sala.

Ao final da intervenção, aos alunos de ambas as turmas foram submetidos a um novo teste, novamente 10 palavras, escolhidas com cautela para que não tivessem sido trabalhadas durante a intervenção. Desta forma, esperou-se observar se os alunos realmente adquiriram consciência fonológica no nível silábico. A preferência por palavras isoladas e não por frases, para os testes, se deu pela hipótese de que não haveria interferência, no caso desta pesquisa, se as palavras fossem analisadas dentro do contexto de uma sentença. $O$ segundo teste serviu de subsídio para a verificação do grau de aproveitamento da intervenção.

Quadro 02: Palavras utilizadas no pós-teste imediato

\begin{tabular}{|c|c|}
\hline Palavras & Transcrição fonética \\
\hline Five & {$[$ farv] } \\
\hline Past & {$[\mathrm{pæst}]$} \\
\hline Age & {$[\mathrm{erd}]$} \\
\hline Red & {$[\mathrm{red}]$} \\
\hline Mate & {$[\mathrm{mett}]$} \\
\hline Work & {$[\mathrm{wrsk}]$} \\
\hline Step & {$[\mathrm{st \varepsilon p}]$} \\
\hline Bed & {$[\mathrm{bed}]$} \\
\hline Stone & {$[\mathrm{stoon}]$} \\
\hline Rap & {$[\mathrm{ræp}]$} \\
\hline \multicolumn{2}{|c|}{ Fonte: própria (2019) } \\
\hline \multicolumn{2}{|c|}{} \\
A última etapa da metodologia de uma pesquisa-ação, segundo Júnior (2010), seria um
\end{tabular}
teste de disseminação, no entanto, não foi possível realizar um teste que medisse a durabilidade dos resultados, pois não houve tempo suficiente na oportunidade deste artigo. Entretanto, esta etapa não impede a verificação da influência da consciência silábica do inglês. 


\section{RESULTADOS E DISCUSSÃO}

Para isso foi feita a transcrição fonética dos testes.

\section{PRÉ-TESTE}

A primeira análise a ser feita foi através do pré-teste. Nesta etapa, buscou-se observar se tais participantes produziam a vogal epentética e em quais casos haviam maiores ocorrências. Embora não tenha sido estabelecido nenhum tempo mínimo ou máximo para a oralização das palavras, $100 \%$ dos participantes falaram uma palavra após a outra, praticamente sem pausa. Pôde-se observar ainda que nenhum deles excedeu o tempo de quinze segundos para oralizar as dez palavras. O tempo de produção oscilou de 8 a 15 segundos entre os participantes.

Detectou-se que: dos 21 (vinte e um) participantes, 19 (dezenove), equivalente à $90,47 \%$, produziram inadequadamente a vogal /i/ por paragoge em pelo menos duas das dez palavras do pré-teste. Cabe dizer que somente dois participantes $(9,53 \%)$ pronunciaram todas as palavras corretamente. Esse acréscimo, conforme Alves (2004), é fruto de um reparo silábico. Já que raramente consoantes assumem posição de coda no português, o falante tende a acrescentar uma vogal final na pronúncia, adaptando os padrões estrangeiros aos nativos: “o falante do português brasileiro tende, tipicamente, a inserir uma vogal após a consoantes final. Este aspecto é típico da pronúncia do falante brasileiro de inglês" (SILVA, 2015, p. 59).

Em relação à quantidade de participantes por palavra que transformaram palavras monossílabas em dissílabas segue o quadro:

Quadro 03: Participantes por palavra que acrescentaram o /i/ final inadequadamente

\begin{tabular}{|c|c|}
\hline Palavra e transcrição fonética & Porcentagem de erro por palavra \\
\hline Cup $[\mathrm{k} \wedge \mathrm{p}]$ & 12 participantes $(57,14 \%)$ \\
\hline Robe $[\mathrm{rovb}]$ & 17 participantes $(80,95 \%)$ \\
\hline Job $[\mathrm{d}$ sab] & 15 participantes $(71,43 \%)$ \\
\hline Club $[\mathrm{kl} \Lambda \mathrm{b}]$ & 13 participantes $(61,90 \%)$ \\
\hline Stamp $[$ stcemp] & 9 participantes $(42,86 \%)$ \\
\hline Black $[\mathrm{blæk}]$ & 10 participantes $(47,62 \%)$ \\
\hline Flag $[$ flag $]$ & 12 participantes $(57,14 \%)$ \\
\hline Horse $[$ hors] & 5 participantes $(23,81 \%)$ \\
\hline Have $[\mathrm{hæv}]$ & 12 participantes $(57,14 \%)$ \\
\hline Word $[\mathrm{w} 3 \mathrm{rd}]$ & 5 participantes $(23,81 \%)$ \\
\hline
\end{tabular}

Analisando a quantidade por turma, tem-se que os alunos da turma pesquisa apresentaram um apuramento de quase $30 \%$ a mais de erro que os alunos da turma de controle.

Observou-se também que as maiores incidências de erros ocorreram nas palavras "robe, Job e club", todas terminadas em /b/, um dos casos em que o falante brasileiro tende a inserir 
uma vogal i após a consoante segundo Silva (2015). A palavra "robe" constou o maior índice de erros. Supõe-se que o motivo esteja relacionado à vogal "e" final presente na escrita, como mencionado por Silveira (2004), que pode causar dificuldade ao falante brasileiro, já que no português há a pronuncia do "e" como um /i/ em sílabas finais (pele - ['peli]).

No caso da palavra "horse", que também termina com a vogal ortográfica "e" na última sílaba, e que apresentou um dos menores graus de pronúncia inadequada, relaciona-se, hipoteticamente, ao fato de se tratar de uma palavra mais corriqueira no cotidiano destes alunos, e a pronúncia dela já ter sido "decorada".

\section{PÓS-TESTE}

Os resultados encontrados após a intervenção foram surpreendentes. Depois das aulas de consciência fonológica no nível silábico, um novo teste foi realizado. A porcentagem da ocorrência de erros foi novamente calculada e agora comparada com a do pré-teste.

Quadro 04: Porcentagem por aluno das ocorrências do /i/ final no pré e pós-teste em ambas as turmas

\begin{tabular}{|c|c|c|c|}
\hline \multicolumn{2}{|c|}{ Turma de pesquisa } & \multicolumn{2}{c|}{ Turma de controle } \\
\hline Aluno 1 & $80 \% \rightarrow 0 \%$ & Aluno 1 & $30 \% \rightarrow 60 \%$ \\
\hline Aluno 2 & $60 \% \rightarrow 0 \%$ & Aluno 2 & $20 \% \rightarrow 40 \%$ \\
\hline Aluno 3 & $80 \% \rightarrow 0 \%$ & Aluno 3 & $20 \% \rightarrow 40 \%$ \\
\hline Aluno 4 & $50 \% \rightarrow 0 \%$ & Aluno 4 & $60 \% \rightarrow 0 \%$ \\
\hline Aluno 5 & $50 \% \rightarrow 0 \%$ & Aluno 5 & $30 \% \rightarrow 20 \%$ \\
\hline Aluno 6 & $70 \% \rightarrow 20 \%$ & Aluno 6 & $30 \% \rightarrow 20 \%$ \\
\hline Aluno 7 & $80 \% \rightarrow 0 \%$ & Aluno 7 & $80 \% \rightarrow 50 \%$ \\
\hline Aluno 8 & $0 \% \rightarrow 0 \%$ & Aluno 8 & $0 \% \rightarrow 0 \%$ \\
\hline Aluno 9 & $100 \% \rightarrow 20 \%$ & & \\
\hline Aluno 10 & $90 \rightarrow 0 \%$ & & \\
\hline Aluno 11 & $70 \% \rightarrow 0 \%$ & & \\
\hline Aluno 12 & $50 \% \rightarrow 0 \%$ & & \\
\hline Aluno 13 & $40 \% \rightarrow$ & & \\
\hline
\end{tabular}

Fonte: própria (2019)

Contatou-se que na turma que recebeu a intervenção houve uma redução de 95,12\% na inserção do /i/ final em palavras monossílabas e 10 dos 13 participantes apresentaram 100\% de melhora, levando o número de ocorrências a zero. Já na turma de controle, a melhora fooi de apenas $14,81 \%$, e alguns dos participantes chegaram a aumentar o número do incidências. Devido ao pouco tempo dedicado à pesquisa, pouco foi aprendido na turma de controle, já que não houve um objetivo específico nesta turma.

Das ocorrências que após a intervenção ainda houve desvio do padrão, 75\% pode ter relação com o "e" ortográfico das palavras "age e stone". 
A partir dos testes, foi possível diagnosticar que os participantes também possuem dificuldades no nível fonológicos dos fonemas, como por exemplo: no caso da palavra black ([blæk]) ter sido pronunciada, em alguns casos, como [blek], com a troca do fonema /æ/ por /ع/; também em Rap [ræp] ter sido produzido por alguns participantes como [hep], havendo a substituição da fricativa velar $/ \mathrm{r} /$ pela fricativa glotal $/ \mathrm{h} /$.

Os resultados encontrados corroboram a influência positiva da consciência fonológica no nível silábico defendida por Alves (2012b). Poucas horas de um trabalho específico podem sanar determinados problemas, e ainda descobrir novos.

\section{CONCLUSÕES}

Esta pesquisa buscou intervir num problema de pronúncia comum entre os aprendizes da língua inglesa, principalmente nos níveis iniciais. Para isso, após uma pesquisa inicial (préteste), uma pesquisa-ação se fez necessária a fim de tentar corrigir uma falha de evidenciação de um /i/ em final de palavras.

Desta forma, baseado nos estudos da consciência fonológica, especialmente no nível silábico, provou-se a relevância de um trabalho com foco no input fonético-fonológico dos padrões silábicos da língua inglesa, uma vez que, a partir dos resultados apurados, constatouse grande evolução dos participantes após as etapas metodológicas. Com isso, entende-se que o aprendiz do inglês como L2 precisa de grande conhecimento de regras fonológicas para começar a parar de "adivinhar" os sons da língua alvo, e possivelmente sessar o vício de recorrer à estratégia de usar os sons permitidos no português aplicando-os ao inglês, pois, isso pode comprometer a pronúncia adequada de determinadas palavras.

Alves (2012a, p. 40-41) considera essencial a consciência fonológica para alfabetizadores, professores de segunda língua e fonoaudiólogos, pois fornece subsídios teóricos importantes para a prática pedagógica ou clínica de quem atua na área. Assim, segundo Barreto e Alves (2012b, p. 237-238), “ao professor cabe, além de saber pronunciar os sons de modo o mais semelhantemente possível à língua-alvo, possuir um conhecimento formal a respeito de como as coisas acontecem e por que acontecem, o que implicará um conhecimento teórico a respeito da L2". Quando nem mesmo o professor possui essa consciência, a evolução dos alunos pode ser danificada inconscientemente.

Neste sentido, pesquisas e intervenções voltadas aos outros níveis de consciência fonológica (nível dos fonemas e nível intrassilábico) podem ser necessárias em meio a investigações no nível silábico. Conclui-se que os estudos nesta área, que ainda são poucos, são, 
no entanto, indispensáveis para novas práticas profissionais.

\section{REFERÊNCIAS}

ALVES, Ubiratã Kickhöfel. O papel da instrução explícita na aquisição fonológica do inglês como L2: evidências fornecidas pela teoria da otimidade. 2004. 335 f. Dissertação (Mestrado em Linguística Aplicada)-Escola de Educação. Universidade Católica de Pelotas, Pelotas, 2004.

O que é consciência fonológica. In: Lamprecht et al. Consciência dos sons da língua: subsídios teóricos e práticos para alfabetizadores, fonoaudiólogos e professores de língua inglesa. 2. ed. Porto Agre: Edipucrs, 2012a.

Consciência dos aspectos fonéticos-fnológicos da L2. In: Lamprecht et al. Consciência dos sons da língua: subsídios teóricos e práticos para alfabetizadores, fonoaudiólogos e professores de língua inglesa. 2. ed. Porto Agre: Edipucrs, 2012b.

AQUINO, Carla de. Uma discussão acerca da consciência fonológica em LE: o caminho percorrido por aprendizes brasileiros de inglês na aquisição da estrutura silábica. $133 \mathrm{f}$. Dissertação (Mestrado em Letras) - Pontifícia Universidade Católica do Rio Grande do Sul, Porto Alegre, 2010. Disponível em: http://tede2.pucrs.br/tede2/handle/tede/1941\#previewlink0 Acessado em: 23/01/2019.

BAGNO, Marcos. Gramática histórica: do latim ao português brasileiro. Brasília: UnB, 2007, p. 08-09.

BARRETO, F. M.; ALVES, U. K. O processamento e a produção dos aspectos fonéticosfonológicos da L2. In: Lamprecht et al. Consciência dos sons da língua: subsídios teóricos e práticos para alfabetizadores, fonoaudiólogos e professores de língua inglesa. 2. ed. Porto Agre: Edipucrs, 2012a.

Como inserir o ensino comunicativo de pronúncia na sala de aula de L2. In: Lamprecht et al. Consciência dos sons da língua: subsídios teóricos e práticos para alfabetizadores, fonoaudiólogos e professores de língua inglesa. 2. ed. Porto Agre: Edipucrs, $2012 b$.

BLANCO-DUTRA, A. P.; SCHERER, A. P. R.; BRISOLARA, L. B. Consciência fonológica e aquisição de língua materna. In: Lamprecht et al. Consciência dos sons da língua: subsídios teóricos e práticos para alfabetizadores, fonoaudiólogos e professores de língua inglesa. 2. ed. Porto Agre: Edipucrs, 2012.

DA SILVA, Claudiane Costa; DA SILVA, André Pedro. Epêntese vocálica na escrita: uma abordagem sociolinguística. Anais do SIELP. Volume 2, n. 1. Uberlândia: EDUFU, 2012. LIMA JR., Ronaldo Mangueira. Uma investigação dos efeitos do ensino explícito da pronúncia na aula de inglês como língua estrangeira. Revista Brasileira de Linguística Aplicada, v. 10, n. 3, p. 747-771, 2010. 
SCHERER, Ana Paula Rigatti. Conversa inicial. In: Lamprecht et al. Consciência dos sons da língua: subsídios teóricos e práticos para alfabetizadores, fonoaudiólogos e professores de língua inglesa. 2. ed. Porto Agre: Edipucrs, 2012a.

SILVA, Thais Cristofer. Pronúncia do Inglês: para falantes do português brasileiro. 2. ed. São Paulo: Contexto, 2012.

SILVEIRA, Rosane et al. The influence of pronunciation instruction on the perception and production of English word-final consonants. 2004. 